07

\title{
Наногетероструктуры AllnGaPAs/GaAs/Si для фотоэлектрических преобразователей, полученные методом импульсного лазерного напыления
}

\author{
(С) Л.С. Лунин ${ }^{1,2}$, М.Л. Лунина ${ }^{1,}$, А.Е. Казакова ${ }^{2}$, А.С. Пащенко ${ }^{1}$, \\ Д.Л. Алфимова ${ }^{1}$, Д.А. Арустамян ${ }^{2}$ \\ ${ }^{1}$ Южный научный центр РАН, Ростов-на-Дону, Россия \\ ${ }^{2}$ Южно-Российский государственный политехнический университет \\ (НПИ) им. М.И. Платова, Новочеркасск, Россия \\ E-mail: lunin_ls@mail.ru
}

Поступило в Редакцию 24 сентября 2018 г.

Методом импульсного лазерного напыления получены наногетероструктуры AlInGaPAs/GaAs/Si для каскадных фотоэлектрических преобразователей, работающих в интервале длин волн 300-1300 nm. Исследованы структурные и люминесцентные свойства нанопленок AlInGaPAs на GaAs и GaAs на Si. Изучены спектральные характеристики фотоэлементов трехкаскадного фотоэлектрического преобразователя AlInGaPAs/GaAs/Si.

DOI: 10.21883/PJTF.2018.24.47033.17537

Создание высокоэффективных фотоэлектрических преобразователей (ФЭП), состоящих из соединений $\mathrm{A}^{3} \mathrm{~B}^{5}$, выращенных на дешевых кремниевых подложках, является одной из приоритетных задач современной фотовольтаики [1,2]. Наибольшая эффективность преобразования солнечной энергии в электрическую достигается при использовании каскадных солнечных элементов [3,4].

Достижение предельных параметров в фотоэлектрических преобразователях возможно при получении гетероструктур с нанослоями твердого раствора, используемого в качестве активной области с высокой фоточувствительностью [5].

Основными проблемами при получении гетероструктур соединений $\mathrm{A}^{3} \mathrm{~B}^{5}$ на подложках кремния являются рассогласование постоянной решетки, а также коэффициентов термического расширения (КТР). 
Различие в этих параметрах порождает возникновение прорастающих дислокаций в эпитаксиальных слоях $\mathrm{A}^{3} \mathrm{~B}^{5}$ и как следствие снижение эффективности солнечных элементов на их основе.

Влияние решеточного рассогласования можно снизить, выращивая слои, близкие по параметру решетки к кремнию, влияние же разницы КТР слоя и подложки снизить более проблематично. Однако уменьшить количество прорастающих дислокаций можно за счет низких температур выращивания слоев.

Наиболее перспективным в этом отношении методом, обеспечивающим низкозатратный рост нанопленок $\mathrm{A}^{3} \mathrm{~B}^{5}$, является метод импульсного лазерного напыления (ИЛН) [6]. Важным достоинством метода ИЛН кроме уже упомянутого низкотемпературного роста нанопленок является точный контроль толщины эпитаксиальной пленки.

Цель настоящей работы состоит в получении наногетероструктур AlInGaPAs/GaAs/Si для ФЭП методом ИЛН и исследовании их спектральных характеристик.

Наногетероструктуры AlInGaPAs/GaAs/Si выращивались с применением технологического комплекса импульсного лазерного напыления, созданного на базе вакуумной камеры установки „Varicoat-430A“ и $\mathrm{AYG}: \mathrm{Nd}^{3+}$-лазера. Процесс напыления осуществлялся путем распыления мишеней GaAs и синтезированного поликристалла AlInGaPAs [7] лазерным излучением второй гармоники $\mathrm{AYG}: \mathrm{Nd}^{3+}$-лазера в вакуумной камере. Энергия лазерного импульса составляла $110 \mathrm{~mJ}$ при длительности импульса в $15 \mathrm{~ns}$, частота повторения импульсов была равна $50 \mathrm{~Hz}$. Расстояние от поверхности мишени до подложки составляло $50 \mathrm{~mm}$. Процесс синтеза проводился согласно схеме последовательных операций с применением процедуры термоциклирования, описанной нами ранее в работе [6].

Для предотвращения появления микрокапель на поверхности синтезируемых нанопленок использовался метод механической сепарации осажденных частиц. В качестве сепаратора применялась комбинация двух сеток, вибрирующих с частотой $100 \mathrm{~Hz}$. Диаметр ячейки сетки составляет $1 \mathrm{~mm}$.

В качестве подложек использовались пластины монокристаллического кремния ориентации (100) p-типа с площадью $1.5 \mathrm{~cm}^{2}$. Очистка поверхности кремниевых подложек от органических загрязнений проводилась в смеси изопропанола и ацетона в ультразвуковой ванне с последующим травлением 5\% раствором плавиковой кислоты для

Письма в ЖТФ, 2018, том 44, вып. 24 


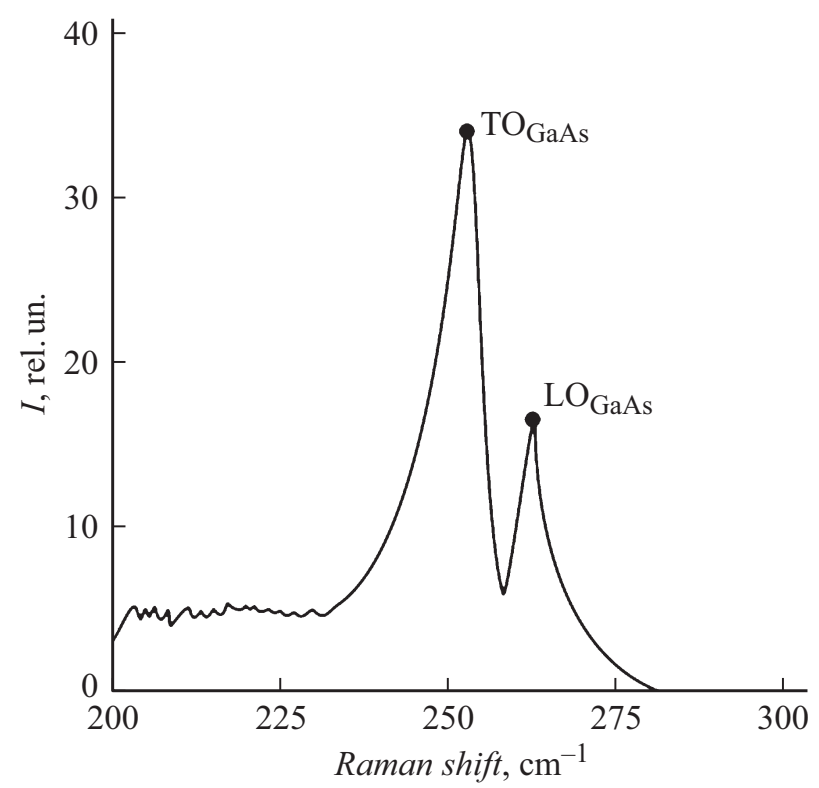

Рис. 1. Спектры комбинационного рассеяния света нанопленки арсенида галлия на кремнии.

удаления естественного оксидного слоя и пассивации поверхности атомами водорода.

В процессе ИЛН первого каскада в подложках $p$-Si происходит формирование неглубокого ( 150-200 nm) $p$-n-перехода, обусловленного диффузией атомов мышьяка в поверхностный слой подложки, что делает подложку не только несущей, но и активной, т.е. образуется нижний солнечный элемент $n-\mathrm{Si} / p-\mathrm{Si}$.

При лазерном напылении используются два типа мишеней $p$-GaAs и n-GaAs, что позволяет создавать второй каскад толщиной $\sim$ 300-400 nm. Аналогичным образом получался третий каскад в твердом растворе AlInGaPAs.

Полученные на подложках кремния нанослои GaAs были исследованы методом рамановской спектроскопии и рентгеновской дифракции. На рис. 1 представлен спектр комбинационного рассеяния света одного из образцов GaAs на подложке кремния, ориентированной в плоскости

Письма в ЖТФ, 2018, том 44, вып. 24 


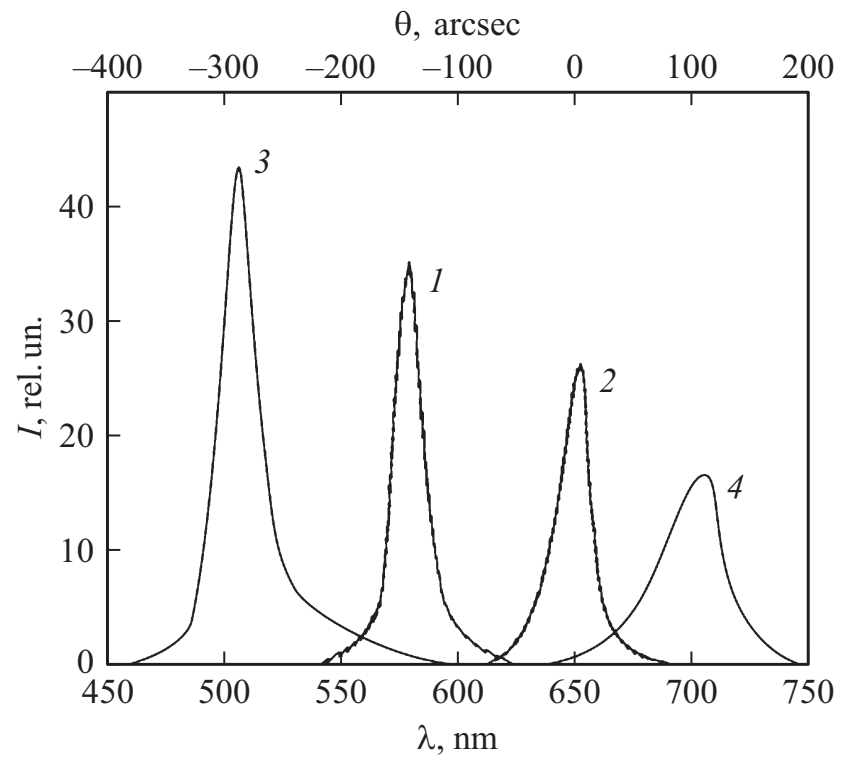

Рис. 2. Кривые дифракционного отражения $(1,2)$ и спектры ФЛ $(3,4)$ пленок AlInGaPAs $(1,3)$ и GaAs $(2,4)$.

(100). В спектре присутствуют две полосы с частотами $260 \mathrm{~cm}^{-1}$ (TO) и $268 \mathrm{~cm}^{-1}$ (LO), которые соответствуют собственным частотам колебаний чистого арсенида галлия. Наличие в спектре образцов продольных колебаний (LO) свидетельствует о довольно низком содержании примесей в слое GaAs. По смещению пиков фононных мод можно судить о том, что величина механических напряжений пленки невелика.

Присутствие четких дифракционных пиков (рис. 2, кривые 1,2) указывает на наличие кристаллической структуры нанопленок AlInGaPAs и GaAs с учетом значения ширины дифракционных кривых на уровне половинной амплитуды $\left(\mathrm{FWHM}_{\mathrm{GaAs}}=32^{\prime \prime}, \mathrm{FWHM}_{\mathrm{AlInGaPAs}}=18^{\prime \prime}\right)$.

Спектры фотолюминесценции (ФЛ) (рис. 2, кривые 3,4), измеренные при $300 \mathrm{~K}$, подтвердили качество получаемых нанопленок AlInGaPAs и GaAs. Для пятикомпонентных нанопленок AlInGaPAs интенсивность пика ФЛ выше и ширина полосы излучения на половине

Письма в ЖТФ, 2018, том 44, вып. 24 


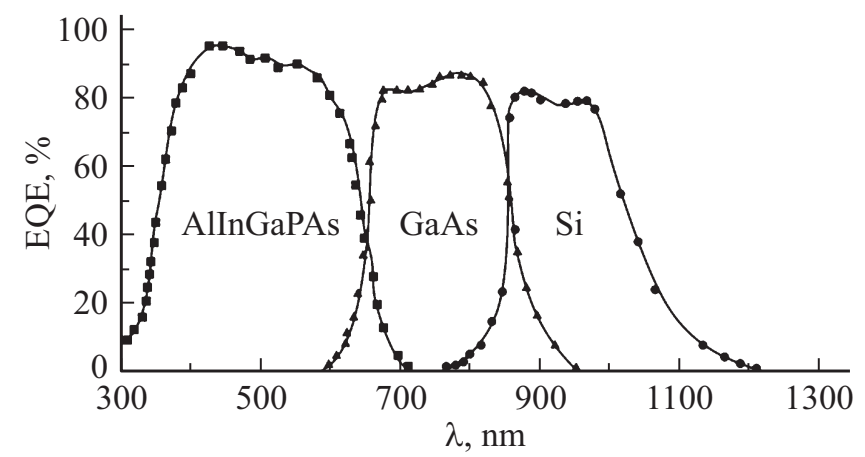

Pис. 3. Спектры внешней квантовой чувствительности фотоэлементов трехкаскадного наногетероструктурного ФЭП.

максимума меньше, чем для нанопленок GaAs. Это связано с тем, что гетероструктура AlInGaPAs/GaAs полностью согласована по параметрам постоянной решетки и КТР в отличие от $\mathrm{GaAs} / \mathrm{Si}$.

На основе наногетероструктур AlInGaPAs/GaAs/Si был реализован трехкаскадный ФЭП, имеющий высокие значения внешнего квантового выхода (рис. 3). За счет использования твердого раствора AlInGaPAs в качестве широкозонного окна удалось достичь внешнего квантового выхода 90\% в спектральном диапазоне $340-550 \mathrm{~nm}$.

Таким образом, рассмотренный в работе метод импульсного лазерного напыления позволяет получать наногетероструктуры AlInGaPAs/GaAs/Si для трехкаскадных ФЭП, причем при напылении пленки GaAs на подложку кремния $p$-типа проводимости и дальнейшем термоциклировании в подложке создается $p-n$-переход между подложкой $p-\mathrm{Si}$ и слоем $n-\mathrm{Si}$, возникающий в результате диффузии атомов мышьяка. Данный $p-n$-переход может быть использован в качестве узкозонного (нижнего) элемента в каскаде со средним элементом GaAs в высокоэффективных каскадных солнечных элементах. Следует отметить, что при ИЛН кремний является не только пассивной подложкой, но и активной частью каскадных элементов. Использование пятикомпонентного твердого раствора AlInGaPAs, изопараметрического c GaAs, широкозонного окна и активной области в качестве верхнего солнечного элемента трехкаскадного ФЭП позволяет значительно расширить коротковолновую часть солнечного спектра.

Письма в ЖТФ, 2018, том 44, вып. 24 
Работа выполнена в рамках государственного задания (грант № 16.4757.2017/8.9), а также при финансовой поддержке РФФИ в рамках научного проекта № 17-08-01206 А.

\section{Список литературы}

[1] Jain N., Hudait M.K. // Energy Harvesting Syst. 2014. V. 1. N 3-4. P. 121-145. DOI: 10.1515/ehs-2014-0012

[2] Krier A., Yin M., Marshall A.R.J., Krier S.E. // J. Electron. Mater. 2016. V. 45. N 6. P. $2826-2830$. DOI: $10.1007 / \mathrm{s} 11664-016-4373-0$

[3] Албёров Ж.И., Андреев В.М., Румянщев В.Д. // ФТП. 2004. Т. 38. В. 8. С. 937 948.

[4] Alferov Zh.I. , Andreev V.M. , Rumyantsev V.D. // Springer Ser. in Optical Sciences. 2007. V. 130. P. 25-50. DOI: 10.1007/978-3-540-68798-6_2

[5] Чеботарев С.Н., Пащенко А.С., Лунина М.Л. // Вестн. Южного научного центра РАН. 2011. Т. 7. № 4. С. 25-30.

[6] Лунин Л.С., Лунина М.Л., Девицкий О.В., Сысоев И.А. // ФТП. 2017. Т. 53. B. 3. C. 403-408. DOI: 10.21883/FTP.2017.03.44216.8299

[7] Алфимова Д.Л., Лунина М.Л., Чеботарев С.Н., Пащенко А.С., Лунин Л.С., Казакова А.Е. // Неорган. материалы. 2017. Т. 53. В. 12. С. 1245-1256. DOI: $10.7868 / \mathrm{S} 0002337 \mathrm{X} 17120016$ 